\title{
Evaluation of Tolerability of Trifluridine/Tipiracil Combination Tablet in Patients With Advanced/Recurrent Colorectal Cancer
}

\author{
MICHIO KIMURA ${ }^{1}$, EISEKI USAMI ${ }^{1}$, HITOMI TERAMACHI ${ }^{2}$ and TOMOAKI YOSHIMURA ${ }^{1}$ \\ ${ }^{1}$ Department of Pharmacy, Ogaki Municipal Hospital, Ogaki, Japan; \\ ${ }^{2}$ Laboratory of Clinical Pharmacy, Gifu Pharmaceutical University, Gifu, Japan
}

\begin{abstract}
Aim: This study aimed to clarify the tolerability of a trifluridineltipiracil combination tablet (TAS-102) in patients with advanced or recurrent colorectal cancer over 75 years of age. Patients and Methods: Patients were divided into groups under the age of 75 years $(n=62)$, and 75 years and over $(n=17)$. The treatment period with TAS-102 tablet, reasons for discontinuation, adverse events (AEs), and overall survival (OS) were compared between the groups. Results: The incidence of AEs (including neutropenia, anemia, nausea, malaise, and anorexia) was similar for both groups and the treatment enforcement periods for different regimens were not statistically significant between the groups ( $p=0.207)$. No major differences were observed in the reasons for discontinuation, such as AEs or progressive disease, between the two groups. Conclusion: TAS-102 therapy for advanced/recurrent colorectal cancer is considered to be highly tolerable in patients 75 years and older. These findings are important for $A E$ monitoring and guidance for patients taking TAS-102.
\end{abstract}

In recent years, major advances have been made in chemotherapy for colorectal cancer (CRC), which has been shown to reduce tumour growth and improve patient prognosis (1). The recommended first- and second-line chemotherapies for advanced/recurrent CRC include: fluorouracil, leucovorin, and oxaliplatin (collectively known as FOLFOX) paired with bevacizumab; capecitabine and oxaliplatin paired with bevacizumab; fluorouracil/leucovorin and irinotecan (FOLFIRI) paired with bevacizumab; FOLFOX paired with cetuximab/panitumumab; or FOLFIRI paired with cetuximab/ ramucirumab (2-4). The American Society of Clinical

Correspondence to: Michio Kimura, Department of Pharmacy, Ogaki Municipal Hospital, 4-86 Minaminokawa-cho, Ogaki-shi, Gifu 503-8502, Japan. Tel: +81 584813341, Fax: +81 584770854, e-mail: kimkim0305nao@yahoo.co.jp

Key Words: Elderly, tolerance, advanced/recurrent colorectal cancer, TAS-102.
Oncology and the National Comprehensive Cancer Network recommend regorafenib or trifluridine/tipiracil combination tablet (TAS-102) as late-line treatments for CRC. In Japan, TAS-102 is widely used as third-line treatment for CRC (5). The primary adverse events (AEs) induced by TAS-102 include neutropenia $(73.1 \%)$, decrease in haemoglobin (63.9\%), nausea (63.0\%), and anorexia (55.5\%) (6). Myelosuppression, infections, and interstitial lung disease have also been reported as serious AEs (7).

Elderly patients can be less tolerant of anticancer drugs due to reduced renal/hepatic function. TAS-102 is an antimetabolite that contains trifluridine and tipiracil hydrochloride (at a molar ratio of 1:0.5) and is renally excreted (8). Japan has an aging society where the population of citizens over the age of 75 years is expected to continue growing. While it is predicted that elderly patients will use TAS-102 more frequently, there is no information available on the safety profile of the drug in patients aged 75 years and older. Elderly patients are presumed to have a higher rate of serious AEs, such as bone marrow suppression, due to decreased renal function. In this study, we made use of AE monitoring and patient guidance to evaluate the tolerability of TAS-102 in elderly patients with CRC who received this medication.

\section{Patients and Methods}

Patients and methods. The present study retrospectively surveyed 84 patients with pathologically confirmed metastatic or recurrent colorectal adenocarcinoma treated with TAS-102 at Ogaki Municipal Hospital (Ogaki, Japan) between July 2014 and August 2018. Patients who migrated from regorafenib to TAS-102 $(n=5)$ were excluded. Patients were divided into those under the age of 75 years $(n=62)$, and those aged 75 years and over $(n=17)$. Patient characteristics, AEs, treatment period, reasons for discontinuation, and overall survival (OS) were analysed retrospectively using data collected from the electronic charts and pharmacy service records. OS was defined as the interval between the initiation of TAS-102 and the date of death from any cause. AEs were evaluated according to the Common Terminology Criteria for Adverse Events, version 4.0 (9), and the most severe grades during chemotherapy were reported. Personal information was protected in the aggregated data. 
The Institutional Review Board of Ogaki Municipal Hospital, Ogaki, Japan, approved this study (approval number: 20181122-3).

Treatment: Trifluridine/tipiracil combination tablet (Lonsurf). A trifluridine/tipiracil combination tablet (with each dose at $35 \mathrm{mg} / \mathrm{m}^{2}$ body surface area) was administered twice daily after morning and evening meals for 5 days, followed by 2 days of rest, then again for 2 weeks, followed by a 14-day rest period. This regimen constituted one treatment cycle and was repeated every 4 weeks. Treatment was continued until discontinued due to progressive disease (PD), AEs, deterioration in performance status (PS), or deterioration of condition.

Statistical analysis. The F-test was performed to compare the two groups. Mann-Whitney's $U$-test or the chi-square test of independence (Fisher's exact probability test) was used to analyse patient characteristics, AEs, and reasons for discontinuation. The Kaplan-Meier log-rank test was used to compare OS. Significance was set at $p<0.05$, and all statistical analyses were performed in EZR (v1.30; Saitama Medical Center, Jichi Medical University, Saitama, Japan), which is a graphical user interface for R (The R Foundation for Statistical Computing, Vienna, Austria) (10).

\section{Results}

Patient characteristics. The patient characteristics are summarized in Table I. The median age was 76 years (range $=75-83$ years) in the older group and 67 years (range: $37-74)$ in the younger group. The creatinine clearance $(\mathrm{CrCl})$ was significantly lower in the elderly group (median $56.0 \mathrm{vs}$. $78.3 \mathrm{mg} / \mathrm{ml} ; p<0.001)$.

Analysis of AEs. The major AEs for TAS-102 are summarized in Table II. In the younger group, these mainly consisted of neutropenia $(56.5 \%)$, anaemia $(50.0 \%)$, nausea $(50.0 \%)$, malaise $(35.5 \%)$, and anorexia $(29.0 \%)$, while in the elderly group, neutropenia $(76.5 \%)$, anaemia $(70.6 \%)$, malaise (35.3\%), nausea $(29.4 \%)$, and aspartate aminotransferase/alanine aminotransferase (AST/ALT) $(29.4 \%)$ increases were observed. Neutropenia of grade 3 or higher was observed in 21 out of 62 patients $(33.9 \%)$ in the younger group and in seven out of 17 patients $(41.2 \%)$ in the elderly group $(p=0.577)$.

Treatment period and reasons for discontinuation. The period of treatment with TAS-102 was 95 days (range=6803 ) for the younger group and 105 days (range-23-368) for the elderly group $(p=0.207)$. In the younger group, reasons for discontinuation included AEs in six patients, progressive disease (PD) in 19, deterioration in performance status (PS) in 24, and deterioration of condition in six. Reasons for discontinuation in the elderly group included AEs in two patients, PD in six, deterioration in PS for four, and deterioration of condition in four. Discontinuation of treatment in both the younger and elderly groups due to AEs also included observations of nausea, vomiting, diarrhoea, and stomatitis (Table III).
Table I. Patient characteristics.

\begin{tabular}{|c|c|c|c|}
\hline & $\begin{array}{l}\text { Young } \\
\text { group }\end{array}$ & $\begin{array}{l}\text { Elderly } \\
\text { group }\end{array}$ & $p$-Value \\
\hline Number & 62 & 17 & \\
\hline \multicolumn{4}{|l|}{ Age, years } \\
\hline Median (range) & $67(37-74)$ & $76(75-83)$ & $<0.001$ \\
\hline \multicolumn{4}{|l|}{ Gender, $\mathrm{n}$} \\
\hline Male & 23 & 10 & $0.108^{a}$ \\
\hline Female & 39 & 7 & \\
\hline \multicolumn{4}{|c|}{$\begin{array}{l}\text { ECOG performance } \\
\text { status, } n\end{array}$} \\
\hline 0 & 43 & 15 & $0.313^{\mathrm{a}}$ \\
\hline 1 & 16 & 2 & \\
\hline 2 & 3 & 0 & \\
\hline \multicolumn{4}{|c|}{ Previous treatment lines, $\mathrm{n}$} \\
\hline Median (range) & $2(1-6)$ & $2(1-3)$ & $0.328^{b}$ \\
\hline \multicolumn{4}{|c|}{ Body surface area, $\mathrm{m}^{2}$} \\
\hline Median (range) & $1.53(1.25-1.67)$ & $1.49(1.14-1.96)$ & $0.438^{\mathrm{b}}$ \\
\hline \multicolumn{4}{|l|}{$\mathrm{CrCl}, \mathrm{mg} / \mathrm{ml}$} \\
\hline Median (range) & $78.3(40.0-158.1)$ & $56.0(19.0-96.5)$ & $<0.001^{\mathrm{b}}$ \\
\hline \multicolumn{4}{|l|}{ Unresectable, n } \\
\hline Yes & 30 & 6 & $0.337^{\mathrm{a}}$ \\
\hline \multicolumn{4}{|l|}{ Recurrent, $\mathrm{n}$} \\
\hline Yes & 32 & 11 & \\
\hline \multicolumn{4}{|l|}{ KRAS status, $\mathrm{n}$} \\
\hline Wild-type & 27 & 6 & $0.541^{\mathrm{a}}$ \\
\hline Mutant & 35 & 11 & \\
\hline \multicolumn{4}{|c|}{ Number of metastases } \\
\hline Median (range) & $2(1-3)$ & $2(1-3)$ & $0.747^{b}$ \\
\hline \multicolumn{4}{|l|}{ Metastatic site, $\mathrm{n}$} \\
\hline Liver & 38 & 11 & $0.739^{\mathrm{a}}$ \\
\hline Lung & 22 & 7 & \\
\hline Peritoneal & 21 & 4 & \\
\hline Lymph node & 21 & 4 & \\
\hline Bone & 5 & 0 & \\
\hline Skin & 1 & 0 & \\
\hline Other & 4 & 0 & \\
\hline \multicolumn{4}{|c|}{$\begin{array}{l}\text { Previous anti-EGFR } \\
\text { treatment, } \mathrm{n}(\%)\end{array}$} \\
\hline Yes & $20(32.3)$ & $5(29.4)$ & $0.823^{\mathrm{b}}$ \\
\hline \multicolumn{4}{|c|}{$\begin{array}{l}\text { Previous anti-VEGF } \\
\text { treatment, } \mathrm{n}(\%)\end{array}$} \\
\hline Yes & $46(74.2)$ & $13(76.5)$ & $0.848^{b}$ \\
\hline \multicolumn{4}{|c|}{$\begin{array}{l}\text { Post-treatment use of } \\
\text { TAS-102, n (\%) }\end{array}$} \\
\hline Yes & $6(9.7)$ & $1(5.9)$ & $0.657^{b}$ \\
\hline
\end{tabular}

$\mathrm{CrCl}$ : Creatinine clearance; EGFR: epidermal growth factor receptor; VEGF: vascular epidermal growth factor; TAS102: trifluridine-tipiracil combination tablet. ${ }^{a} \mathrm{Chi}$-square for independence test (Fisher's exact probability test). bMann-Whitney $U$-test.

Overall survival. Figure 1 shows the Kaplan-Meier survival curves for patients following first-line therapy with TAS-102 according to age group. The median OS observed for patients 75 years of age and older $(n=17)$ and those under 75 years $(n=62)$ were 187 days (range $=60-670$ days) and 164 days (range $=37-805$ days), respectively (log-rank test, $p=0.089$ ). 
Table II. Adverse events experienced by patients treated with trifluridine/tipiracil combination tablet (TAS-102) ( $n=79)$.

\begin{tabular}{|c|c|c|c|c|c|c|c|c|c|c|c|c|c|}
\hline \multirow[b]{4}{*}{ Neutropenia } & \multicolumn{6}{|c|}{ Young group $(n=62)$} & \multicolumn{6}{|c|}{ Elderly group $(\mathrm{n}=17)$} & \multirow{4}{*}{$\frac{p \text {-Value }}{0.134}$} \\
\hline & \multirow{3}{*}{$\frac{1}{2}$} & \multicolumn{3}{|c|}{ Grade, $\mathrm{n}$} & \multirow{2}{*}{\multicolumn{2}{|c|}{ All grades $(\%)$}} & \multicolumn{4}{|c|}{ Grade, $\mathrm{n}$} & \multirow{2}{*}{\multicolumn{2}{|c|}{ All grades $(\%)$}} & \\
\hline & & 2 & 3 & 4 & & & 1 & 2 & 3 & 4 & & & \\
\hline & & 12 & 14 & 7 & 35 & 56.5 & 0 & 6 & 5 & 2 & 13 & 76.5 & \\
\hline Thrombocytopenia & 11 & 1 & 1 & 0 & 13 & 21.0 & 2 & 1 & 0 & 0 & 3 & 17.6 & 0.819 \\
\hline Anaemia & 9 & 13 & 9 & 0 & 31 & 50.0 & 6 & 6 & 0 & 0 & 12 & 70.6 & 0.131 \\
\hline T-Bil increase & 1 & 0 & 1 & 0 & 2 & 3.2 & 0 & 0 & 0 & 0 & 0 & 0.0 & 0.453 \\
\hline AST/ALT increase & 5 & 2 & 0 & 0 & 7 & 11.3 & 5 & 0 & 0 & 0 & 5 & 29.4 & 0.484 \\
\hline Creatinine increase & 2 & 0 & 0 & 0 & 2 & 3.2 & 0 & 0 & 0 & 0 & 0 & 0.0 & 0.453 \\
\hline Malaise & 15 & 6 & 1 & 0 & 22 & 35.5 & 6 & 0 & 0 & 0 & 6 & 35.3 & 0.988 \\
\hline Anorexia & 11 & 7 & 0 & 0 & 18 & 29.0 & 2 & 2 & 0 & 0 & 4 & 23.5 & 0.653 \\
\hline Nausea & 26 & 3 & 2 & 0 & 31 & 50.0 & 4 & 1 & 0 & 0 & 5 & 29.4 & 0.131 \\
\hline Vomiting & 3 & 0 & 0 & 0 & 3 & 4.8 & 1 & 0 & 0 & 0 & 1 & 5.9 & 0.861 \\
\hline Stomatitis & 3 & 1 & 1 & 0 & 5 & 8.1 & 0 & 0 & 1 & 0 & 1 & 5.9 & 0.763 \\
\hline Diarrhea & 5 & 0 & 0 & 0 & 5 & 8.1 & 2 & & 0 & 0 & 2 & 11.8 & 0.634 \\
\hline Alopecia & 1 & 0 & - & - & 1 & 1.6 & 0 & 0 & - & - & 0 & 0.0 & 0.698 \\
\hline Dysgeusia & 4 & 0 & - & - & 4 & 6.5 & 0 & 0 & - & - & 0 & 0.0 & 0.282 \\
\hline Headache & 1 & 0 & 0 & 0 & 1 & 1.6 & 0 & 0 & 0 & 0 & 0 & 0.0 & 0.598 \\
\hline Eye disorders (conjunctivitis) & 0 & 0 & 0 & 0 & 0 & 0.0 & 1 & 0 & 0 & 0 & 1 & 5.9 & 0.055 \\
\hline Hyperkalaemia & 0 & 1 & 0 & 0 & 1 & 1.6 & 0 & 0 & 0 & 0 & 0 & 0.0 & 0.598 \\
\hline Cough & 2 & 0 & 0 & - & 2 & 3.2 & 1 & 0 & 0 & - & 1 & 5.9 & 0.611 \\
\hline Constipation & 0 & 0 & 0 & 0 & 0 & 0.0 & 1 & 0 & 0 & 0 & 1 & 5.9 & 0.055 \\
\hline Fever & 3 & 0 & 0 & 0 & 3 & 4.8 & 0 & 0 & 0 & 0 & 0 & 0.0 & 0.355 \\
\hline Pruritus & 1 & 0 & 0 & - & 1 & 1.6 & 0 & 0 & 0 & - & 0 & 0.0 & 0.598 \\
\hline Hoarseness & 0 & 0 & 0 & - & 0 & 0.0 & 1 & 0 & 0 & - & 1 & 5.9 & 0.055 \\
\hline
\end{tabular}

T-Bil: Total bilirubin; AST/ALT: aspartate aminotransferase/alanine aminotransferase. Chi-square for independence test (Fisher's exact probability test).

Subgroup analyses. Efficacies of TAS-102 in the patient subgroups were compared by Kirsten rat sarcoma 2 viral oncogene homolog $(K R A S)$ mutational status. In the younger group, the effect was equivalent regardless of KRAS mutation [OS for KRAS mutant vs. wild-type: 174 (range $=44-549) v s .145$ (range $=37-805)$ days, $p=0.161]$, with a similar finding in the elderly group [183 (range=145-664) vs. 291 (range=126-670) days, respectively; $p=0.295$ ].

The median OS in the younger group in patients who received crossover treatment with TAS-102 to regorafenib was 385 (range $=116-703)$ days, and was $153($ range $=37-805)$ days in patients who received only TAS-102 $(p=0.014)$. OS cannot be similarly compared in the elderly group (Table IV).

\section{Discussion}

In this study, we evaluated the tolerability of TAS-102 in patients with CRC over 75 years of age. In this domestic clinical trial, the occurrence rate of AEs with TAS-102 was 96.6\% (115/119 cases), where frequent AEs were neutropenia (73.1\%), haemoglobin decrease (63.9\%), and nausea (63.0\%). Neutropenia and anaemia were similar in this study compared to other domestic clinical trials (7) and there was no difference in the frequency of expression between elderly patients and young patients. In contrast, nausea was less frequent in this study compared to other domestic clinical trials (7), but no difference was found between elderly and young patients. This may be due to the prescription of antiemetic agents in advance of treatment in this study. No major differences were observed in the reason for discontinuation between elderly and young patients. The discontinuation due to AEs was 8/79 (10.1\%) for both groups; the main causes were nausea, vomiting, diarrhoea and stomatitis. These results reveal that elderly patients can tolerate TAS-102 as well as young patients and discontinuations of use do not increase substantially due to AEs.

In this study, kidney function was significantly rechewed in elderly patients compared to young patients. Yasue et al. reported that decline in renal function was associated with severe neutropenia. In particular, patients with CRC who underwent TAS-102 chemotherapy with a $\mathrm{CrCl}<57.1 \mathrm{ml} / \mathrm{min}$ showed neutropenia of grade 3 or greater (11). Although severe AEs such as neutropenia were expected in elderly patients, since TAS-102 is renally excreted, the results obtained for elderly patients were not statistically different from those obtained for young patients with better renal function. Yasue et al. studied neutropenia during the first 
Table III. Treatment with trifluridine/tipiracil combination tablet (TAS-102).

\begin{tabular}{|c|c|c|c|}
\hline & Young group $(n=62)$ & Elderly group $(\mathrm{n}=17)$ & $p$-Value \\
\hline \multicolumn{4}{|l|}{ Initial dose } \\
\hline Standard dose & 61 & 16 & $0.321^{\mathrm{a}}$ \\
\hline Initially reduced, $\mathrm{n}$ & 1 & 1 & \\
\hline Median (range), mg & $100(80-120)$ & $100(60-110)$ & $0.905^{\mathrm{b}}$ \\
\hline \multicolumn{4}{|l|}{ No. of treatment cycles } \\
\hline Median (range) & $3(1-22)^{*}$ & $3(1-12)$ & $0.252^{\mathrm{b}}$ \\
\hline \multicolumn{4}{|l|}{ Duration of treatment, days } \\
\hline Median (range) & $95(6-803)^{*}$ & $105(23-368)$ & $0.207^{b}$ \\
\hline \multicolumn{4}{|l|}{ Required dose reductions, $\mathrm{n}$} \\
\hline Yes & 7 & 3 & $0.485^{\mathrm{a}}$ \\
\hline \multicolumn{4}{|l|}{ Reasons for discontinuation } \\
\hline Adverse events & 6 & 2 & $0.859^{\mathrm{a}}$ \\
\hline Progressive disease & 19 & 6 & $0.827^{\mathrm{a}}$ \\
\hline Deterioration in performance status & 24 & 4 & $0.179^{\mathrm{a}}$ \\
\hline Deterioration of condition & 6 & 4 & $0.153^{\mathrm{a}}$ \\
\hline Treatment ongoing at data collection & 5 & 0 & NA \\
\hline
\end{tabular}

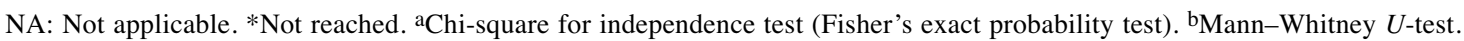

Table IV. Efficacy of trifluridineltipiracil combination tablet (TAS-102) in the subgroup analysis by crossover to regorafenib.

\begin{tabular}{|c|c|c|c|c|c|c|}
\hline \multirow[b]{2}{*}{ Efficacy measure } & \multicolumn{2}{|c|}{ Young group } & \multirow[b]{2}{*}{$p$-Value } & \multicolumn{2}{|c|}{ Elderly group } & \multirow[b]{2}{*}{$p$-Value } \\
\hline & $\begin{array}{l}\text { TAS-102 only } \\
\quad(n=56)\end{array}$ & $\begin{array}{l}\text { Crossover to } \\
\text { regorafenib } \\
\quad(n=6)\end{array}$ & & $\begin{array}{l}\text { TAS-102 only } \\
\quad(n=16)\end{array}$ & $\begin{array}{l}\text { Crossover to } \\
\text { regorafenib } \\
\quad(n=1)\end{array}$ & \\
\hline Median OS (range), days & $153(37-805)^{*}$ & $385(116-703)^{*}$ & $0.014^{\mathrm{a}}$ & $186(60-670)^{*}$ & $579 *$ & NA \\
\hline Median treatment cycles (range), $\mathrm{n}$ & $3(1-22)$ & $4(2-9)$ & $0.391^{\mathrm{b}}$ & $3(1-7)$ & 12 & $0.102^{b}$ \\
\hline Median duration of treatment (range), days & $83(6-803)$ & $145(56-643)$ & $0.024^{b}$ & $98(23-280)$ & 368 & $0.307^{b}$ \\
\hline
\end{tabular}

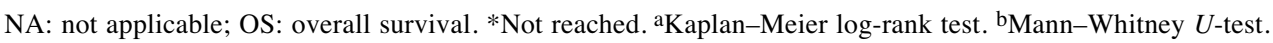

course of TAS-102, but our study considered the worst grade achieved over the entire treatment period, which may explain the difference in observations.

The duration of TAS-102 treatment (younger group: 95 days, elderly group: 105 days) and OS (younger group: 164 days, elderly group: 187 days) were equivalent in elderly and young patients. We consider PS, KRAS status, and crossover treatment from TAS-102 to regorafenib as factors influencing the therapeutic effect. Kwakman et al. reported that PS, KRAS mutation status, white blood cell count, serum lactate dehydrogenase, and alkaline phosphatase were prognostic factors for OS (12).

In this study, there was no difference between the PS of elderly and young patients, therefore no difference existed in the drug effect. There are many reports that patients with wild-type KRAS have better OS than those with mutant KRAS (13-15). KRAS mutation and high Ki-67 expression have been shown to be independent predictors of poor

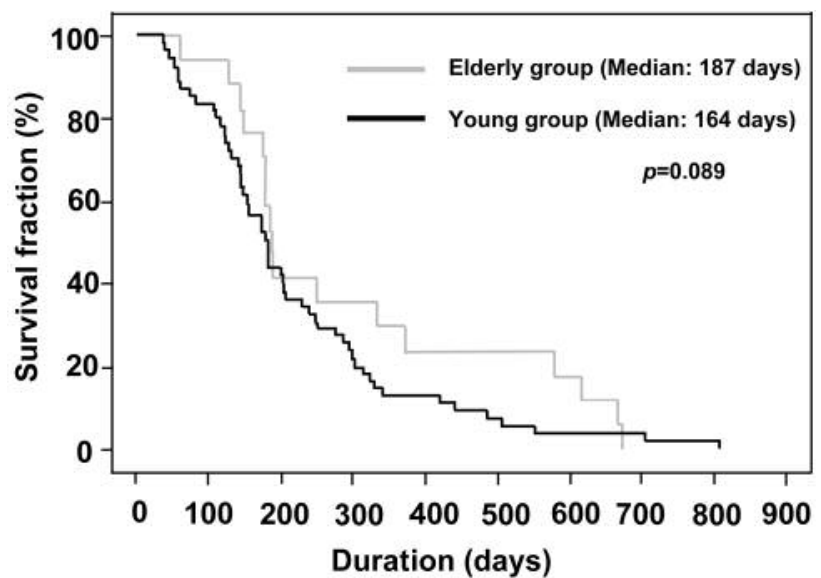

Figure 1. Kaplan-Meier survival curves showing overall survival following first-line therapy with TAS-102 in the two patient groups: those under the age of 75 years and those 75 years of age and older. No significant difference in survival was identified between the groups. 
survival after colon resection (16). Other studies found no relation between KRAS and OS. Chen et al. reported that OS benefits did not correlate with KRAS status or the number of metastatic sites (17). In our study, there was no difference in OS as a function of KRAS status for either elderly patients or young patients. This issue will continue to be the subject of future studies.

There are patients in clinical cases that are only able to use one or two drugs, where regorafenib and TAS-102 are recommended for treatment after third-line therapy, such that prior use of either medicine may affect the OS. Subgroup analysis of Sueda et al. showed that the OS benefit in patients who received crossover treatment with both drugs was significantly larger than that observed for patients who only received one of the two drugs. These data suggest that strategies maximizing the availability of both drugs (regorafenib and TAS-102) can extend the OS in this poor prognostic setting. Sueda et al. did not specify whether regorafenib or TAS-102 should be used first (18). However, Masuishi et al. reported finding no remarkable differences in the efficacy and safety of TAS-102 between patients with and without previous regorafenib treatment and vice versa (19). Van Cutsem et al. reported that age and effect were irrelevant for elderly patients and not related to OS for those aged 65 years and older (14). In our study, patients in the younger group who were able to use regorafenib had significantly better duration of TAS-102 and OS, whereas the number of cases in the elderly group was small and is the subject of future study.

This research is limited by the fact that it was a retrospective survey at a single hospital. Since the results of this study deal only with patients in specific areas, future nationwide surveys involving multicentre collaborations are needed. To our knowledge, this study is the first to analyze the tolerability of TAS-102 in patients with CRC aged 75 years and older. TAS-102 therapy for CRC is considered to be tolerable in patients of all ages. These findings are important for AE monitoring and guidance for patients taking TAS-102.

\section{Conflicts of Interest}

The Authors have declared that no conflict of interest exists in regard to this study.

\section{References}

1 Aiba K, Natori $\mathrm{K}$ and Murakami Y: Advance of salvage chemotherapy for colorectal cancer. Gan To Kagaku Ryoho 42: 394-397, 2015 (In Japanese).

2 Bokemeyer C, Bondarenko I, Hartmann JT, de Braud F, Schuch G, Zubel A, Celik I, Schlichting M and Koralewski P: Efficacy according to biomarker status of cetuximab plus FOLFOX-4 as first-line treatment for metastatic colorectal cancer: the OPUS study. Ann Oncol 22: 1535-1546, 2011.
3 Saltz LB, Clarke S, Díaz-Rubio E, Scheithauer W, Figer A, Wong R, Koski S, Lichinitser M, Yang TS, Rivera F, Couture F, Sirzén $\mathrm{F}$ and Cassidy $\mathrm{J}$ : Bevacizumab in combination with oxaliplatin-based chemotherapy as first-line therapy in metastatic colorectal cancer: A randomized phase III study. J Clin Oncol 26: 2013-2019, 2008.

4 Van Cutsem E, Köhne CH, Láng I, Folprecht G, Nowacki MP, Cascinu S, Shchepotin I, Maurel J, Cunningham D, Tejpar S, Schlichting M, Zubel A, Celik I, Rougier P and Ciardiello F: Cetuximab plus irinotecan, fluorouracil, and leucovorin as firstline treatment for metastatic colorectal cancer: updated analysis of overall survival according to tumor KRAS and BRAF mutation status. J Clin Oncol 29: 2011-2019, 2011.

5 Japanese Society for Cancer of the Colon and Rectum: Japanese Society for Cancer of the Colon and Rectum (JSCCR) guidelines 2014 for treatment of colorectal cancer. Int J Clin Oncol 20: 207239, 2015.

6 Mayer RJ, Van Cutsem E, Falcone A, Yoshino T, GarciaCarbonero R, Mizunuma N, Yamazaki K, Shimada Y, Tabernero J, Komatsu Y, Sobrero A, Boucher E, Peeters M, Tran B, Lenz HJ, Zaniboni A, Hochster H, Cleary JM, Prenen H, Benedetti F, Mizuguchi H, Makris L, Ito M, Ohtsu A; RECOURSE Study Group: Randomized trial of TAS-102 for refractory metastatic colorectal cancer. N Engl J Med 372: 1909-1919, 2015.

7 Yoshino T, Mizunuma N, Yamazaki K, Nishina T, Komatsu Y, Baba H, Tsuji A, Yamaguchi K, Muro K, Sugimoto N, Tsuji Y, Moriwaki T, Esaki T, Hamada C, Tanase T and Ohtsu A: TAS102 monotherapy for pretreated metastatic colorectal cancer: A double-blind, randomised, placebo-controlled phase 2 trial. Lancet Oncol 13: 993-1001, 2012.

8 Lenz HJ, Stintzing S and Loupakis F: TAS-102, a novel antitumor agent: A review of the mechanism of action. Cancer Treat Rev 41: 777-783, 2015

9 US Department of Health and Human Services: Common Terminology Criteria for Adverse Events (CTCAE) version 4.0. Washington, DC: US Department of Health and Human Services, 2010.

10 Kanda Y: Investigation of the freely available easy-to-use software 'EZR' for medical statistics. Bone Marrow Transplant 48: 452-458, 2013

11 Yasue F, Kimura M, Usami E, Iwai M, Kawachi S, Mitsuoka M, Ikeda $\mathrm{Y}$ and Yoshimura T: Risk factors contributing to the development of neutropenia in patients receiving oral trifluridine-tipiracil (TAS-102) chemotherapy for advanced/ recurrent colorectal cancer. Pharmazie 73: 178-181, 2018.

12 Kwakman JJM, Vink G, Vestjens JH, Beerepoot LV, de Groot JW, Jansen RL, Opdam FL, Boot H, Creemers GJ, van Rooijen JM, Los M, Vulink AJE, Schut H, van Meerten E, Baars A, Hamberg P, Kapiteijn E, Sommeijer DW, Punt CJA and Koopman M: Feasibility and effectiveness of trifluridine/tipiracil in metastatic colorectal cancer: Real-life data from the Netherlands. Int J Clin Oncol 23: 482-489, 2018.

13 Kimura M, Iwai M, Usami E, Teramachi H and Yoshimura T: Prognostic factors in patients with advanced and recurrent colorectal cancer receiving last-line chemotherapy. Pharmazie 73: 115-119, 2018.

14 Van Cutsem E, Mayer RJ, Laurent S, Winkler R, Grávalos C, Benavides M, Longo-Munoz F, Portales F, Ciardiello F, Siena S, Yamaguchi K, Muro K, Denda T, Tsuji Y, Makris L, Loehrer P, Lenz HJ, Ohtsu A; RECOURSE Study Group: The subgroups of 
the phase III RECOURSE trial of trifluridine/tipiracil (TAS-102) versus placebo with best supportive care in patients with metastatic colorectal cancer. Eur J Cancer 90: 63-72, 2018.

15 Arita S, Shirakawa T, Matsushita Y, Shimokawa HK, Hirano G, Makiyama A, Shibata Y, Tamura S, Esaki T, Mitsugi K, Ariyama $\mathrm{H}$, Kusaba H, Akashi K and Baba E: Efficacy and safety of TAS102 in clinical practice of salvage chemotherapy for metastatic colorectal cancer. Anticancer Res 36: 1959-1966, 2016.

16 Nash GM, Gimbel M, Shia J, Nathanson DR, Ndubuisi MI, Zeng ZS, Kemeny N and Paty PB: KRAS mutation correlates with accelerated metastatic progression in patients with colorectal liver metastases. Ann Surg Oncol 17: 572-578, 2010.

17 Chen D, Wu YS, Lin H, Wang Y, Li L and Zhang T: Efficacy and safety of TAS-102 in refractory metastatic colorectal cancer: A meta-analysis. Cancer Manag Res 28: 2915-2924, 2018.
18 Sueda T, Sakai D, Kudo T, Sugiura T, Takahashi H, Haraguchi N, Nishimura J, Hata T, Hayashi T, Mizushima T, Doki Y, Mori $\mathrm{M}$ and Satoh T: Efficacy and safety of regorafenib or TAS-102 in patients with metastatic colorectal cancer refractory to standard therapies. Anticancer Res 36: 4299-306, 2016.

19 Masuishi T, Taniguchi H, Hamauchi S, Komori A, Kito Y, Narita Y, Tsushima T, Ishihara M, Todaka A, Tanaka T, Yokota T, Kadowaki S, Machida N, Ura T, Fukutomi A, Ando M, Onozawa Y, Tajika M, Yasui H, Muro K, Mori K and Yamazaki K: Regorafenib versus trifluridine/tipiracil for refractory metastatic colorectal cancer: a retrospective comparison. Clin Colorectal Cancer 16: e15-e22, 2017.

Received December 14, 2018 Revised January 18, 2019 Accepted January 21, 2019 